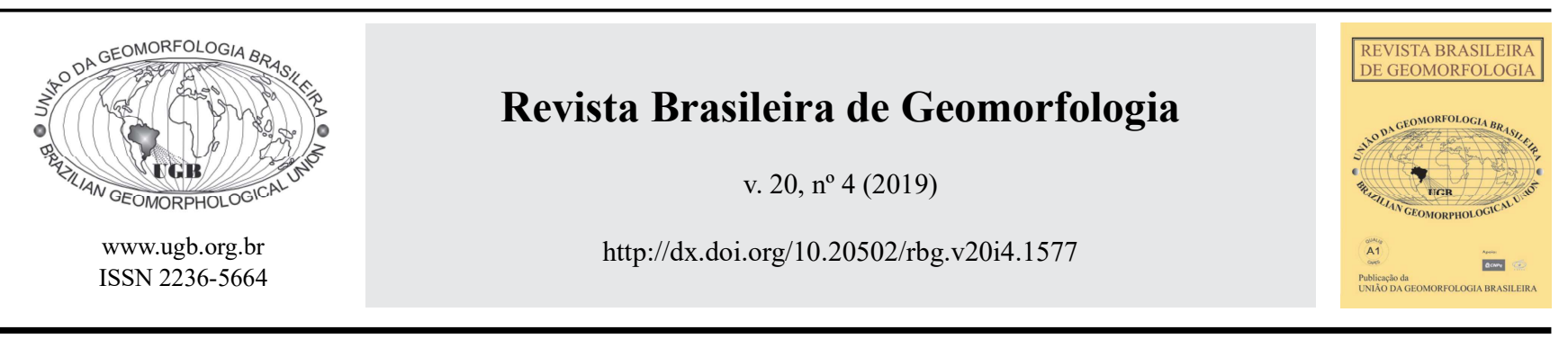

\title{
EVOLUÇÃO DE ESCARPAMENTOS EM MARGENS RIFTE: UMA DISCUSSÃO SOBRE SOERGUIMENTO E DESNUDAÇÃO NA MANTIQUEIRA MERIDIONAL A PARTIR DE MAPAS PALEOTOPOGRÁFICOS E PARÂMETROS GEOMORFOMÉTRICOS
}

\section{ESCARPMENTS EVOLUTION IN RIFT MARGINS: A DISCUSSION ABOUT UPLIFT AND DESNUDACION IN THE MANTIQUEIRA MERIDIONAL FROM PALEOTOPOGRAPHIC MAPS AND GEOMORFOMETRIC PARAMETERS}

Roberto Marques Neto

Departamento de Geociências, Universidade Federal de Juiz de Fora Rua José Lourenço Kelmer, Juiz de Fora, Minas Gerais. CEP: 36036-900. Brasil

ORCID: 0000-0002-6496-789X

E-mail: roberto.marques@ufjf.edu.br

Juliana Alves Moreira

Departamento de Geociências, Universidade Federal de Juiz de Fora Rua José Lourenço Kelmer, Juiz de Fora, Minas Gerais. CEP: 36036-900. Brasil

ORCID: 0000-0001-8041-4462

E-mail: julianaalvesmoreira22@gmail.com

Felipe Pacheco da Silva

Programa de Pós-graduação em Geografia, Universidade Federal do Rio de Janeiro Av. Athos da Silveira Ramos, 274, Rio de Janeiro, Rio de Janeiro. CEP: 21941-916. Brasil

ORCID: 0000-0001-5059-1740

E-mail:feliipe.p@hotmail.com

Informações sobre o Artigo

Recebido (Received):

06/06/2019

Aceito (Accepted):

$12 / 10 / 2019$

\section{Palavras-chave:}

Escarpas Montanhosas; Paleotopografia; Retração de Escarpas; Neotectônica; Margem Rifte.

\section{Keywords:}

Mountain Scarps; Paleotopography; Scarps Retraction; Neotectonic; Rifte Margins.

\section{Resumo:}

O presente artigo tem por objetivo discutir aspectos evolutivos de escarpas em regiões tropicais a partir de estudos na Serra da Mantiqueira Meridional, - Brasil. Os grandes escarpamentos das bordas cratônicas do Brasil Sudeste figuram como sistemas geomorfológicos de evolução complexa que consorcia a regressão das escarpas aos diastrofismos neotectônicos, com basculamentos de blocos coadunando epirogênese positiva e formação de minigrábens. A retração erosiva dos fronts escarpados consorciada às solicitações morfotectônicas foi aqui discutida a partir de uma abordagem integrada, articulando o uso de mapas paleotopográficos e técnicas morfométricas aptas ao estudo de escarpas montanhosas e verificação de esforços tectônicos associados. Os resultados mostraram evidências de regressão em termos qualitativos e quantitativos, com soerguimento e formação de patamares escalonados, realçando o papel da tectônica cenozoica na manutenção dos grandes escarpamentos. 


\begin{abstract}
:
This paper aims to discuss evolutionary aspects of escarpments in tropical regions by studying the Meridional Serra Mantiqueira, - Brazil. The great escarpments of the cratonic borders of Southeastern Brazil appear as geomorphological systems of complex evolution that consort the regression of escarpments to the neotectonic diastrophisms, with blocks tipping combining positive epirogenesis and formation of minigrabens. The erosive retraction of the steep fronts consorted to the morphothectonic requests was discussed here from an integrated approach, articulating the use of paleotopographic maps and morphometric techniques suitable for the study of mountainous escarpments and verification of associated tectonic efforts. The results showed evidences of regression in quality e quantity terms, as uplift and formations of staggered levels, emphasizing the role of the Cenozoic tectonics in the maintenance of great escarpments.
\end{abstract}

\section{Introdução}

Os grandes escarpamentos das margens rifte tropicais figuram como áreas siálicas caracterizadas por elevada energia erosiva, altas taxas de desnudação geoquímica e controle tectônico contundente. Consubstanciam sistemas geomorfológicos da mais alta expressão na compartimentação do relevo nas bordas cratônicas das plataformas herdadas do Gondwana e posicionadas nos cinturões intertropicais. No Brasil Sudeste, essa tipicidade geomorfológica ocorre em grandes estruturas de orientação geral NE-SW dispostas paralela a subparalelamente a partir da linha de costa em demanda aos domínios intracratônicos. Tais escarpamentos herdados da orogenia proterozoica e reativados na fase sin-rifte também foram alvo de solicitações tectônicas durante todo o Cenozoico.

A fachada atlântica do sudeste brasileiro é marcada pela ocorrência de grandes escarpamentos. O primeiro deles é dado pela Serra do Mar, cujo alinhamento geral NE-SW acompanha a linha de costa, malgrado suas reentrâncias e anfractuosidades. $\mathrm{O}$ segundo conjunto é dado pela chamada Serra da Mantiqueira, que avulta em um nível planáltico ainda mais elevado uma vez transposto o gráben do rio Paraíba do Sul. Esse nível planáltico se dissocia em um ramo meridional correspondente ao grande horst, que em alguns segmentos definem extensões interfluviais contínuas acima de 2000 metros, e uma porção setentrional formada por cristas mais baixas e festonadas interceptando morrarias intermontanas. No extremo nordeste se sobressaem o horst da Serra do Brigadeiro, que se eleva acima de 1500 metros, e do Caparaó, antiforme cuja cimeira define o cume mais elevado de todo o Brasil Centro-oriental (Pico da Bandeira, $2892 \mathrm{~m}$ ).

Regiões escarpadas apresentam organizações ero- sivas peculiares, com capturas fluviais conspícuas na morfogênese interfluvial, conforme discutido por Cherem et al. (2013) no contexto dos escarpamentos do Brasil Sudeste. Em alguns compartimentos o controle ativo sobreleva alguns blocos diferencialmente e mantém o facetamento das escarpas de falha; em outros, os escarpamentos se encontram mais reafeiçoados pela dissecação fluvial. Os grandes escarpamentos vinculados ao sistema rifte continental do Brasil Sudeste (sensu RICCOMINI, 1989) tem sua evolução controlada por diferentes níveis de base, do nível do mar aos níveis de base interiores, locais e regionais, posicionados em diferentes patamares altimétricos. Indubitavelmente, a geomorfogênese desses sistemas é complexa, com muitos aspectos ainda a serem desvelados.

O uso de mapas paleotopográficos, executados a partir da rotina metodológica Seppômen (MOTOKI et al., 2008), tem sido adotado em complementação a um conjunto de abordagens que vem sendo correlacionadas em pesquisas levadas a cabo na região dos grandes escarpamentos. Os mapas Seppômen ou de nivelamento dos topos (summit level map) figuram como abordagens cartográficas (COUTO et al., 2012; VARGAS, 2017) que revelam a configuração geral do relevo anterior à dissecação atual, em um período estimado com base nas dimensões das células para as quais o procedimento é executado. Ainda que não figure como uma técnica geocronológica, tem potencial de gerar informações retroativas do relevo com representação cartográfica em diferentes escalas têmporo-espaciais, subsidiando estudos de cunho evolutivo. Nessa linha, o presente artigo assume o intuito investigar aspectos inerentes à evolução de escarpamentos na margem continental brasileira, explorando os potenciais dos mapas paleotopográficos, aplicados em conjunto à mensuração de índices geomórficos e interpretação das capturas fluviais existentes. A área de estudo se aloca 
no contexto geomorfológico da Mantiqueira Meridional (sensu GATTO et al. 1983), e corresponde ao conjunto das altas cristas quartzíticas festonadas (MARQUES NETO,
2017), posicionadas na extremidade meridional da Zona da Mata Mineira e fortemente representativa desses sistemas geomorfológicos (figura 1).

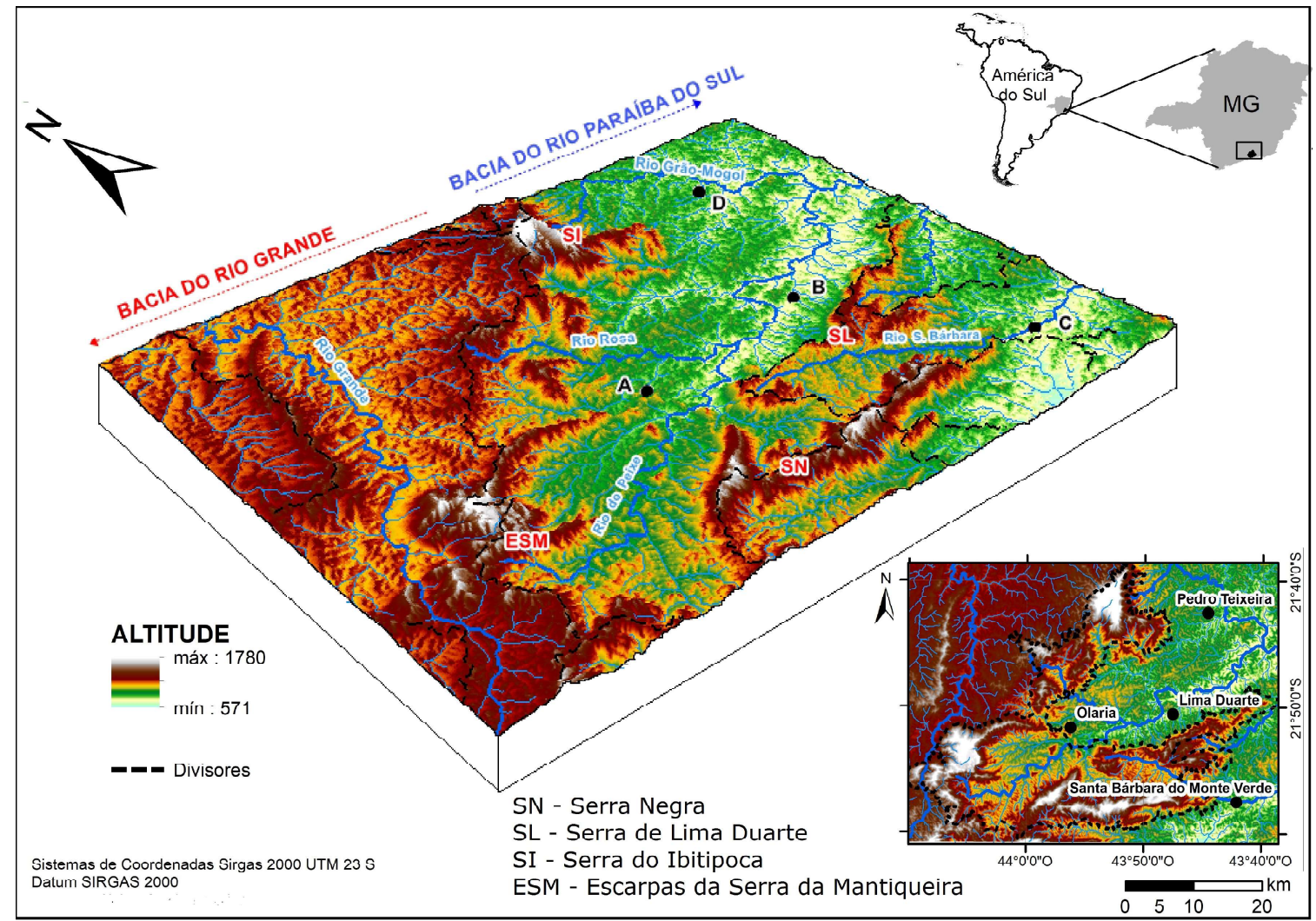

Figura 1 - Localização da área de estudo.

\section{Procedimentos metodológicos}

Os mapas Seppômen, documentos cartográficos representativos do paleorrelevo, foram divulgados no Brasil por Motoki et al. (2008), e sua técnica tem por lógica maior o preenchimento de vales (LEVERINGTON e TELLER, 2003; COUTO et al., 2014; VARGAS, 2017). A rotina metodológica consiste na divisão da área de estudo em células quadráticas sobrepostas às bases planialtimétricas. Para cada célula é considerada a curva de nível mais elevada, o que implica na remoção das demais curvas de nível e na consequente eliminação do efeito da dissecação fluvial, resultando assim em uma configuração geomorfológica anterior a abertura mais recente do vale pelo entalhe vertical dos canais. Posteriormente os valores são interpolados por procedimentos analógicos ou digitais para a geração do mapa paleotopográfico.

A escala de trabalho e as dimensões das células contidas na grade influenciam sobremaneira os resul- tados obtidos pela técnica Seppômen. É sugestivo que células de maiores dimensões sejam empregadas em áreas de expressão espacial significativa, enquanto os estudos em áreas mais restritas, como pequenas bacias hidrográficas e compartimentos geomorfológicos adotem quadrículas menores pela necessidade de uma maior densidade de pontos com informação altimétrica. A dimensão temporal dos mapas paleotopográficos gerados pelos protocolos aqui expostos é deveras relativa, mas é coerente afiançar que células maiores expressam uma temporalidade mais remota, porém uma configuração topográfica menos precisa em função da supressão de informações altimétricas em cada quadrícula. Por outro lado, células menores são interceptadas por menos curvas de nível e assim perdem menos informação, resultando em uma representação mais precisa da paleotopografia; em contrapartida, remetem a uma temporalidade mais restrita. Essa lógica interpretativa já fora exposta por Motoki et al. (2008), Motoki et al. (2012) e Couto et al. (2014). 
Diante das influências escalares que permeiam a técnica Seppômen, que ainda carecem de testes e discussões, foram utilizadas três malhas para a simulação dos mapas paleotopográficos para a região das cristas quartzíticas, quais sejam: $0,5 \mathrm{~km} \times 0,5 \mathrm{~km}, 1,0 \mathrm{~km} \times$ $1,0 \mathrm{~km}$ e $2,0 \mathrm{~km} \times 2,0 \mathrm{~km}$. Em complemento, foram gerados perfis paleotopográficos para as três malhas mensuradas, sendo em cada um deles inserido também o perfil topográfico atual para fins de comparação e observação mais precisa da dissecação fluvial. Nessa fase, os três mapas paleotopográficos foram comparados ao quadro hipsométrico atual, sendo todos eles gerados na escala de 1/50.000 em software ArcGIS.

A rotina de geração dos mapas de paleorrelevo se deu pelo protocolo IDW, lançando-se mão do recurso de interpolação. A partir dos cartogramas que foram gerados para as três malhas e para a topografia atual, procedeu-se na mensuração aproximada do recuo da escarpa, relacionando as rupturas de declive atuais e as paleorupturas obtidas com a interpolação. Foram feitas medições em pontos regularmente distanciados em 1 $\mathrm{km}$, totalizando 634 pontos de medição.

Associadamente aos mapas paleotopográficos foi mensurado o índice geomórfico Sinuosidade da Escarpa Montanhosa (Smf) (BULLe WALLACE, 1985), adequado para estudos em regiões escarpadas, e que foi aqui conjugado diretamente ao Seppômen. O índice em questão é dado pela fórmula $(\mathrm{Smf}=\mathrm{Ls} / \mathrm{Lmf})$, onde $\mathrm{Ls}$ corresponde ao comprimento da escarpa medido no seu sopé, a partir da ruptura de declive com os compartimentos adjacentes, e Lmf é o comprimento da sua projeção retilínea. Valores mais elevados indicam uma escarpa mais retrabalhada e dissecada, enquanto resultados menores, próximos de 1,0 , sinalizam controle ativo e soerguimento do bloco. $\mathrm{O}$ índice foi mensurado para as escarpas atuais e para aquelas geradas pelo Seppômen nas três malhas empregadas, para auxiliar a discussão da evolução das cristas a partir da observação da sequência de valores obtidos.

Em complemento, foram interpretadas e anotadas as capturas fluviais para posterior representação cartográfica. O papel das capturas tem sido amplamente discutido na evolução de escarpas, bordas planálticas e outros sistemas geomorfológicos (BISHOP, 1995; CHEREM et al. 2013; SANTOS, 2017; SALGADO et al. 2018). A interpretação se deu sobre as folhas topográficas em escala de 1/50.000 (Santana do Garambéu, SF-23-X-C-V-2; Santa Rita de Jacutinga, SF-23-Z-C-II-2; Santa Bárbara do Monte Verde, SF-23-X-C-VI-1; Lima Duarte,
SF-23-X-C-VI-3; Bias Fortes, SF-23-X-C-VI-1; Bom Jardim de Minas, SF-23-X-C-V-4). O sentido da captura também foi observado no intuito de averiguar possíveis direções preferenciais para correlação com processos de retração ou manutenção das escarpas em suas relações com as bacias capturadas e captoras.

As expedições de campo foram executadas para fins de reconhecimento do sistema geomorfológico em seus aspectos gerais, bem como nas suas especificidades. Nesse sentido, as primeiras campanhas foram voltadas para a interpretação das organizações geomorfológicas regionais e compartimentação do relevo. Doravante, os expedientes se voltaram para a conferência in locu de respostas dadas pelas técnicas adotadas e para o reconhecimento de evidências de controle tectônico no relevo e na drenagem.

Finalmente, os resultados foram discutidos dialogicamente no contexto da evolução das escarpas, procurando atentar para as influências concernentes aos diferentes controles, ativos e passivos, atuando na evolução do relevo regional.

\section{Resultados e discussão}

O ramo mais setentrional da chamada Mantiqueira Meridional (sensu GATTO et al. 1983) é caracterizado por uma unidade morfoestrutural designada por cristas quartzíticas festonadas (MARQUES NETO, 2017), desarticuladas pela passagem da rede de drenagem que demanda o rio Paraíba do Sul e ladeadas por morrarias intermontanas forjadas em relevos tipicamente mamelonares de grande expressão espacial no sudeste de Minas Gerais. Os domínios altimontanos das cristas são balizados por litotipos quartzíticos intercalados a lentes mais finas de gnaisses e xistos, e os morros convexos intermontanos tem como embasamento fundamental rochas gnáissicas migmatizadas ou isentas de migmatização, que deram margem à geração de espessos mantos de intemperismo (figura 2).

No contexto do horst da Mantiqueira Meridional, as altas cristas quartzíticas avultam no setor pertencente à bacia do rio Paraíba do Sul, contrariando a drenagem invertida que demandou o rio Paraná, a exemplo do rio Grande e principais afluentes e subafluentes (Aiuruoca, Verde, Sapucaí, etc.). Durante o soerguimento da fachada atlântica engendrado pelo rifteamento plataformal, instaurou-se a drenagem dual caracterizada por dois sistemas hidrográficos distintos: para o interior, rios extensos e bacias hidrográficas ultradesenvolvidas que 
excedem os terrenos cristalinos e adentram as bacias de sinéclise fanerozoicas; para o leste, rios de extensão mais restrita, voltados diretamente ao Atlântico (ou com níveis de base muito próximos ao nível geral) que dissecam as antéclises cristalinas e os grábens associados. Em relação à Mantiqueira Meridional, uma importante especificidade a se destacar é a não inversão do rio
Preto, que ao início do processo de tafrogenia começou a organizar uma rede de drenagem contrária aquela comandada pelo rio Grande. A orientação adotada seguiu a do sistema rifte (NE-SW), porém controlada pelo próprio alinhamento do front da Serra da Mantiqueira em soerguimento, demandando diretamente ao gráben dissecado pelo rio Paraíba do Sul.

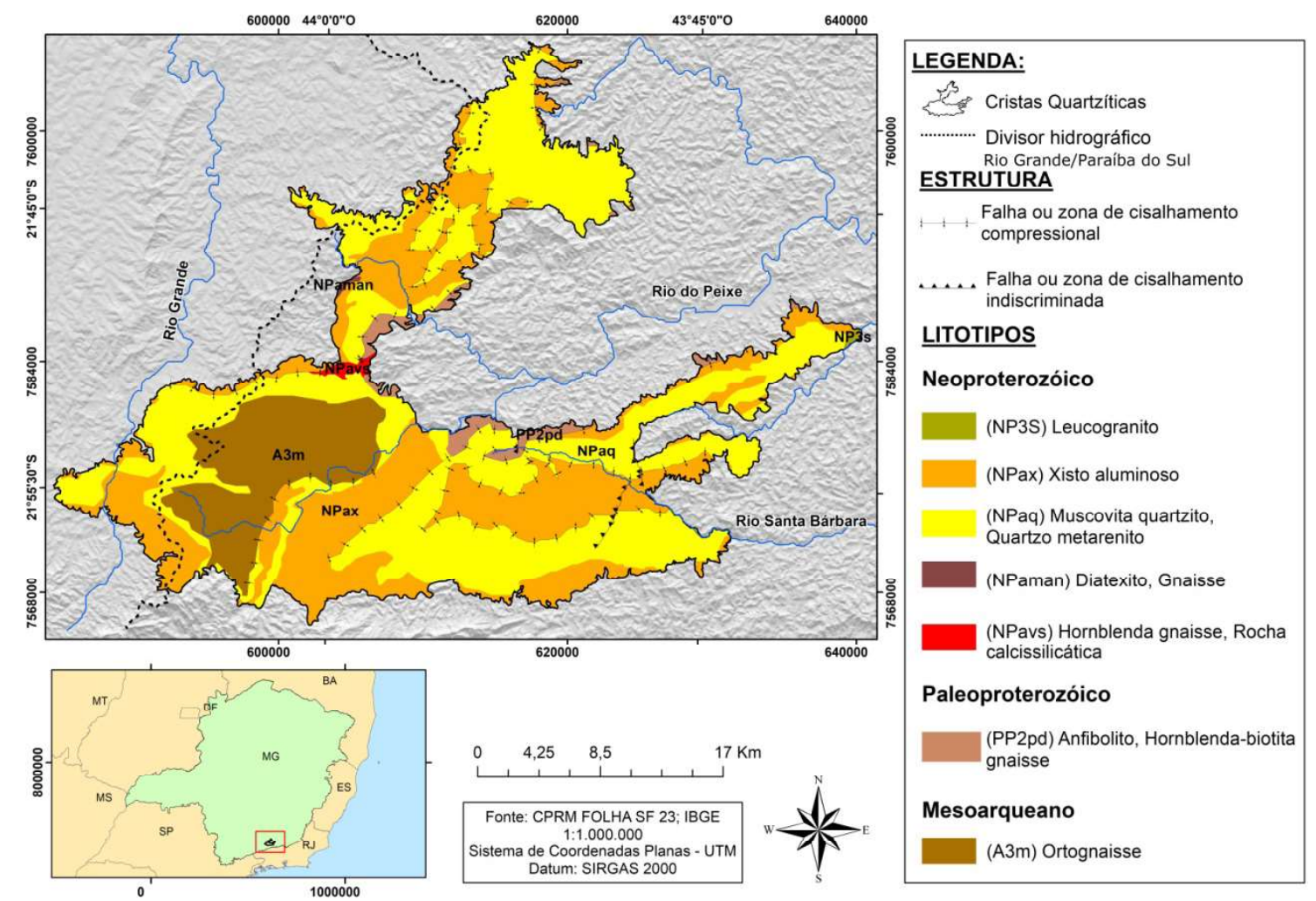

Figura 2 - Esboço geológico da área de estudo.

A passagem do rio Preto impôs intensa atividade de dissecação levada a cabo pelos seus afluentes da margem esquerda, que se organizam a partir do nível de base regional estabelecido pelo tronco coletor principal. Entre os afluentes diretos do rio Preto, o rio do Peixe e a drenagem fluvial a ele relacionada é que exercem influência direta na evolução das cristas em apreço. O referido canal impõe um nível de base bem marcado na faixa altimétrica de 700 metros, pelo qual intercepta as cristas ao transpor o nível planáltico do alto rio Grande, escavando gargantas em linhas de fraqueza e níveis xistosos menos resistentes. Dos flancos escarpados da margem atlântica até a emergência dos grandes escarpamentos interiores ocorrem sucessivos níveis de base escalonados comandando processos geomórficos próprios e integrados em fluxos de ma- téria e energia, e essa configuração geomorfológica tem sido crucial na evolução geomórfica da área de estudo, tal como no contexto dos relevos montanhosos do sudeste brasileiro.

Construídas as referências gerais concernentes à espacialidade do relevo e seus aspectos genético-evolutivos, apresentamos a sequência dos mapas de paleorrelevo gerados pela concepção metodológica Seppômen para interpretações tangentes à evolução mais recente das escarpas montanhosas. Da maneira que as figuras revelam, foram elaborados cartogramas em três malhas quadráticas: $2 \mathrm{~km} \times 2 \mathrm{~km}$ (figura 3), 1 $\mathrm{km} \times 1 \mathrm{~km}$ (figuras 4) e 0,5 km $\times 0,5 \mathrm{~km}$ (figuras 5). Subsequentemente, são apresentados perfis topográficos sobrepostos aos perfis paleotopográficos obtidos em três transectos (figura 6). 
Neto R. M. et al.

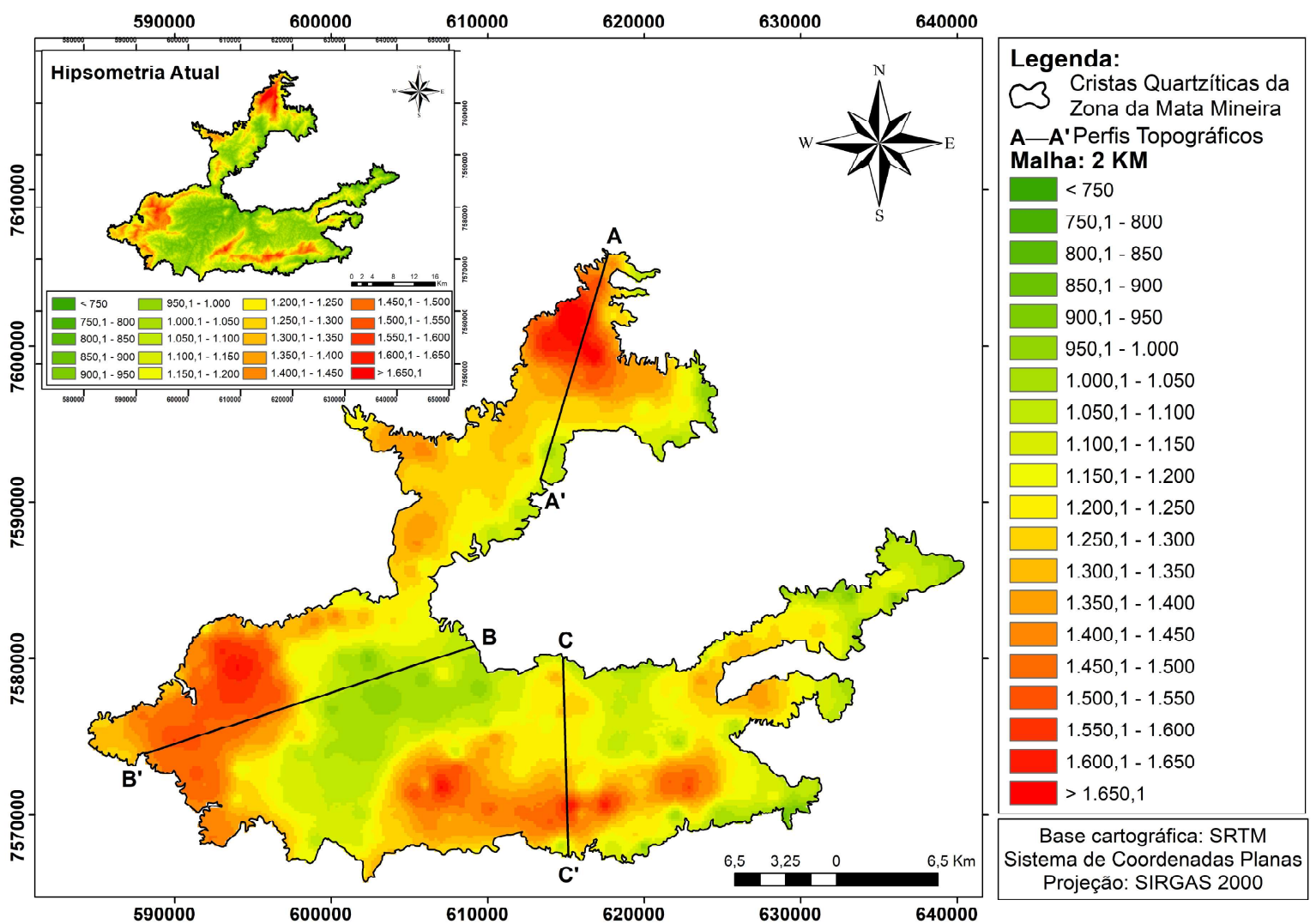

Figura 3 - Paleorrelevo na região das cristas quartzíticas festonadas - malha de $2 \mathrm{~km} \times 2 \mathrm{~km}$.

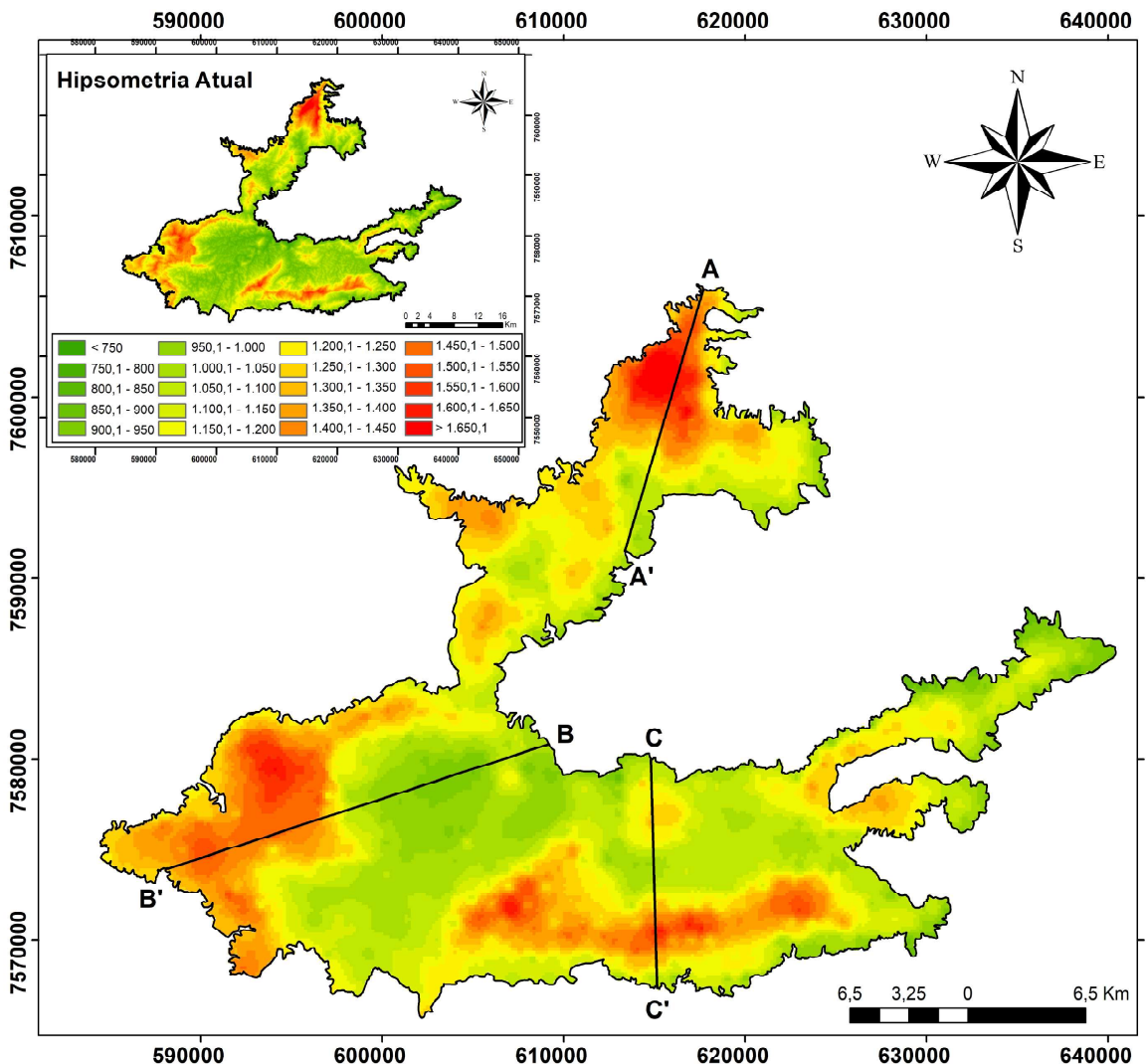

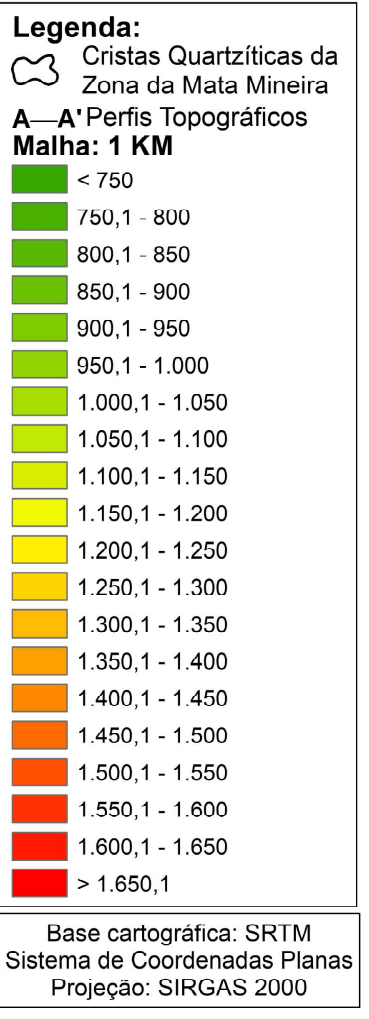

Figura 4 - Paleorrelevo na região das cristas quartzíticas festonadas-malha de $1 \times 1 \mathrm{~km}$. 
Caracterização da Rede de Drenagem e do Sistema Lacustre da Bacia do Rio Grande: Oeste da Bahia

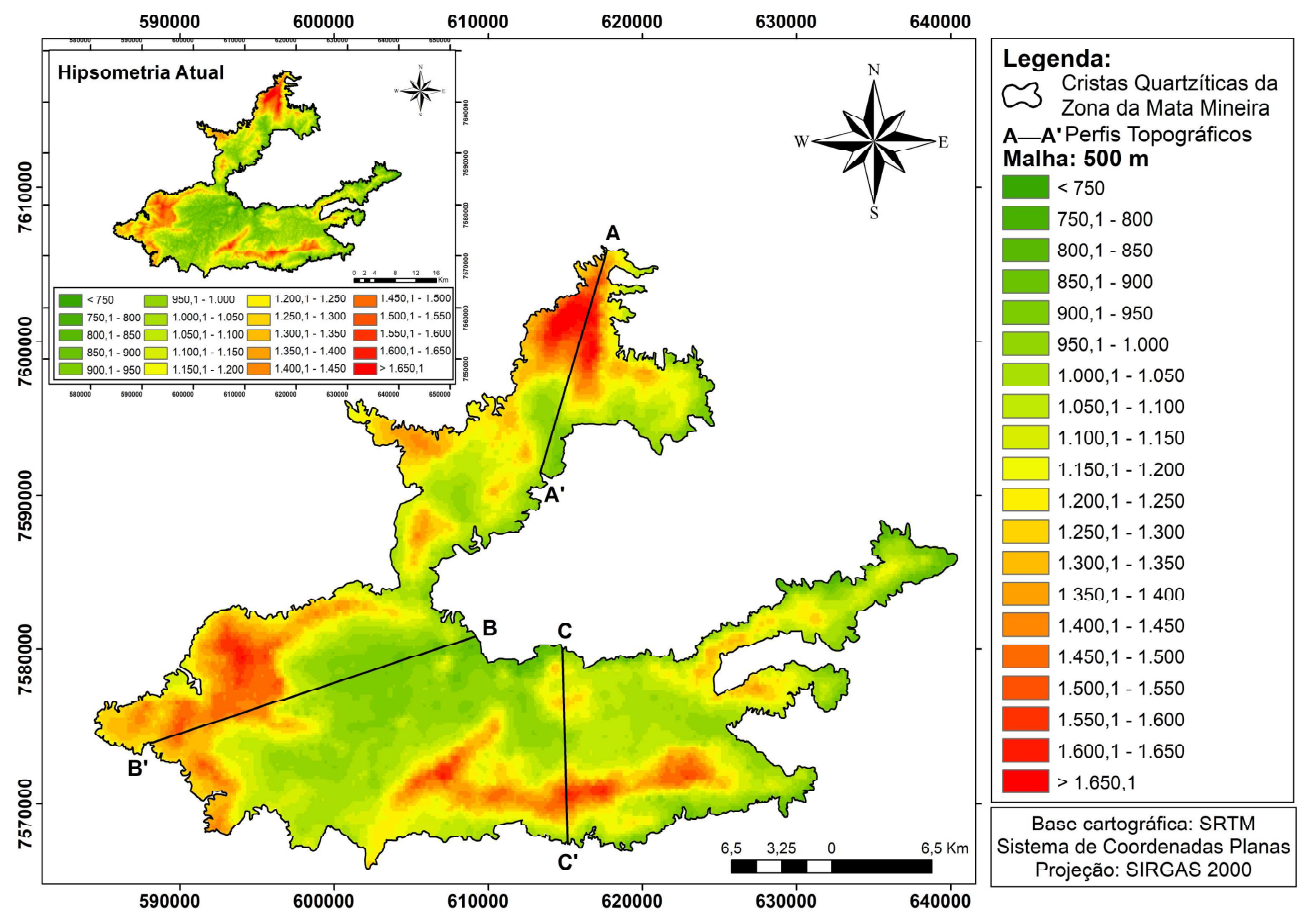

Figura 5 - Paleorrelevo na região das cristas quartziticas festonadas - malha de 0,5 $\mathrm{km} \times 0,5 \mathrm{~km}$
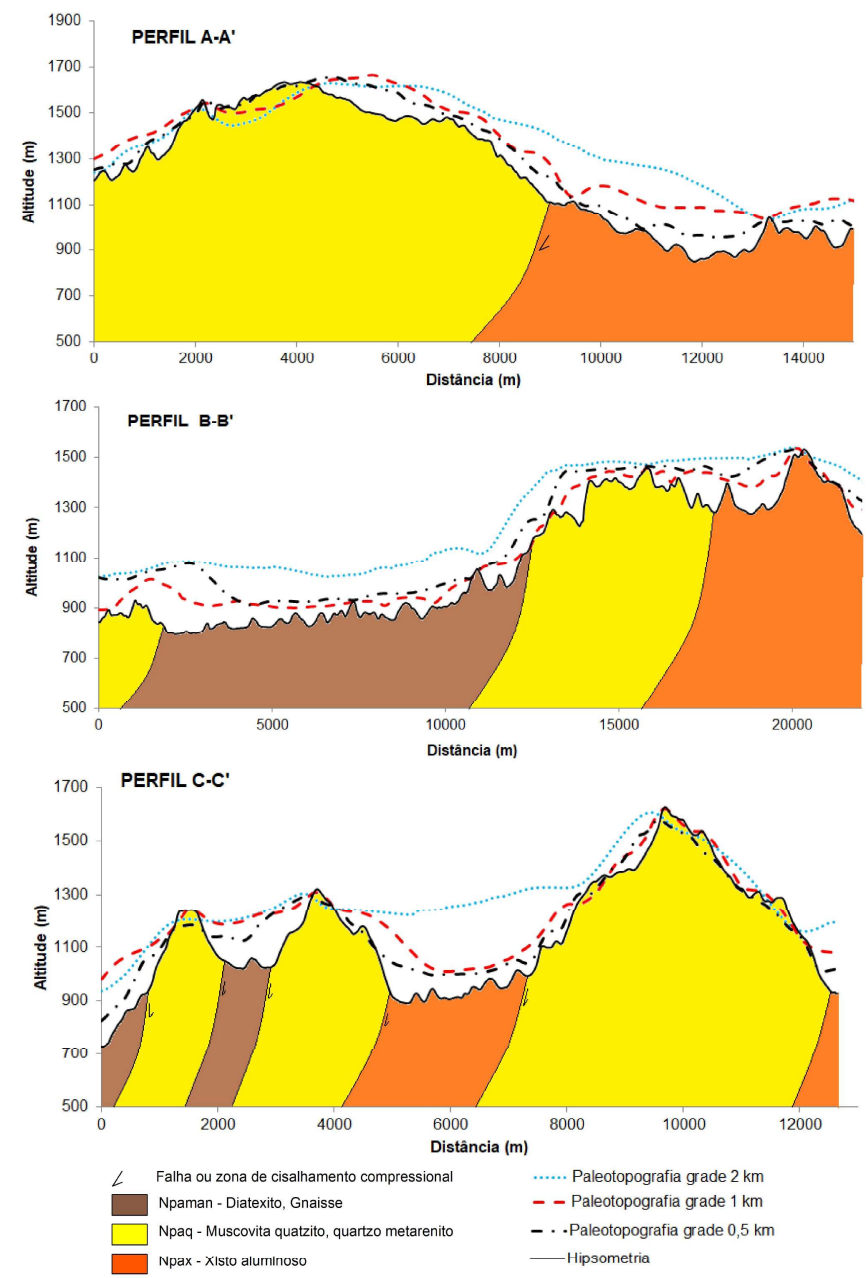

Figura 6 - Perfis topográficos e paleotopográficos obtidos em três transectos. Os litotipos são representados apenas em função dos contatos laterais, não guardando as proporções em espessura e os ângulos de mergulho. 
A comparação entre os produtos cartográficos gerados faz notar que nos ambientes altimontanos, correspondente às cristas quartzíticas, os níveis de cimeira eram flagrantemente mais contínuos e as dimensões interfluviais mais avantajadas, com interflúvios mais largos tanto no alinhamento posicionado a oeste, que delimita a passagem para a bacia do alto rio Grande, como nas cristas tendencialmente $\mathrm{E}-\mathrm{W}$, correspondentes à Serra Negra e à Serra de Lima Duarte.

$\mathrm{Na}$ Serra do Ibitipoca (figura 1), alinhamento divisório à bacia do rio Grande, faixas contínuas acima de 1300 metros não mais ocorrentes em tempos hodiernos conectavam cumeeiras acima de 1700 metros nas extremidades norte e sul. O perfil A-A' que tangencia esse compartimento revela que o entalhe vertical foi pronunciado, o que gerou interflúvios locais estreitos e fortes desníveis. As altitudes máximas foram mantidas nos cumes que tangem os divisores locais, a despeito da evolução lateral das vertentes impulsionada pelo aprofundamento dos níveis de base ali posicionados. A entrada erosiva do ribeirão do Salto, nesse caso, estabeleceu a linha mestra na qual se articulou a retração das escarpas que limitam este que é o patamar mais elevado de todo o conjunto das altas cristas quartzíticas. É visível nos perfis comparativos (A-A') o consumo de patamares e a amplificação do gradiente de canais fluviais, com acentuação do declive, deslocamento remontante dos nicks e migração de surgências hídricas para segmentos mais baixos, indicando o caráter ativo da falha. Também é notória a maior elevação atual da extremidade norte da área de estudo no mesmo transecto, correspondente às superfícies de cimeira da Serra do Ibitipoca, distintamente acima das paleosuperfícies obtidas para as duas malhas maiores e se ajustando apenas na grade de 0,5 $\times 0,5$ (figura 5).

Na Serra Negra, os níveis médios das cimeiras interfluviais estavam sustentados acima de 1400 metros, com nítidas ligações pretéritas com a Serra de Lima Duarte estabelecidas em dois ramos: um na extremidade leste e o outro no extremo oeste, conforme revelado no perfil C-C' da figura 3 (malha 2,0 $\times 2,0$ ). Esse perfil intercepta os dois alinhamentos paralelos mostrando que a dissecação vertical foi significativa no contexto desses dois horsts, bem como no domínio intermontano adjacente, sugerindo controle morfotectônico no abatimento do gráben dissecado pelo ribeirão Monte Verde e seus afluentes. Note-se, a esse respeito, que as malhas menores $(1,0 \times 1,0$ e $0,5 \times 0,5)$ são mais semelhantes entre si, sugerindo que o abatimento do gráben é um processo recente, ainda que se considere a limitação dessa técnica para informações cronológicas. A presença de terraços com horizontes orgânicos desnivelados em relação aos ambientes com hidromorfia ativa, bem como a ocorrência de paleocanais registrados em linhas de seixos arredondados, evidenciam a existência de paleosuperfícies quaternárias e reforçam a hipótese de um controle tectônico ativo na região.

Esse padrão difere do que foi verificado no domínio intermontano interceptado pelo perfil B-B', que revela um rebaixamento mais uniforme das morrarias que ladeiam as cristas. Sincronicamente, a erosão remontante de canais importantes como o rio do Salto, Grão Mogol e Caí retrabalharam progressivamente as escarpas que dividem as águas da bacia do rio do Peixe com o alto Rio Grande. No contexto da Serra Negra e da Serra de Lima Duarte, a expansão erosiva do rio São João e do rio Monte Verde foi decisiva para acarretar a desconexão entre as referidas estruturas.

Os compartimentos intermontanos também apresentavam, presumivelmente, altitudes médias mais elevadas durante tempos mais remotos do Neógeno, anteriormente às incisões mais recentes da drenagem, com escalonamento bem marcado em direção às cristas, porém quase sempre acima de 1000 metros; níveis mais baixos foram averiguados para a malha de $2 \times 2 \mathrm{~km}$ apenas na extremidade nordeste da área de estudo, nos controles finais da zona de cisalhamento que concerne a Serra de Lima Duarte (figura 3). Nos blocos baixos a drenagem provavelmente estava mais encaixada, com estocagem sedimentar mais restrita em comparação aos dias atuais.

O contato entre os compartimentos altimontanos e intermontanos era estabelecido por cristas retilíneas e escarpas mais contínuas. O escalonamento dos mapas, da malha mais grossa para a mais fina, sinaliza a existência de um processo retrativo das escarpas acompanhado de uma evolução vertical e lateral dos vales que se dá tanto nas altas cristas como nas terras mais baixas, onde foi constatado um decréscimo das altitudes médias atuais para níveis abaixo de 800 metros. Essas faixas hipsométricas mais baixas se organizam de forma retilínea, acusando o arranjo recente dos vales fluviais que demandam o rio do Peixe, a 700 metros de altitude. $\mathrm{O}$ festonamento que o referido rio exerce é verificado no ponto de maior estreitamento da estrutura NE-SW, formando-se uma garganta pela qual os canais da alta 
bacia do rio do Peixe adentram o Planalto do Alto Rio Grande. Na malha mais grossa verifica-se o provável estágio inicial do festonamento, inferido pelas altitudes sensivelmente mais elevadas em relação às altitudes médias dos blocos rebaixados entre os horsts. Na malha intermediária uma incisão vertical do rio do Peixe já é notada, evoluindo para o nivelamento verificado nos dias atuais, quando o controle desse nível de base se torna mais extensivo. Pelo que os cartogramas sinalizam, o processo de incisão vertical foi relativamente rápido, formando pisos nivelados ao rio do Peixe e consequente coalescência de algumas planícies.

A regressão das escarpas, pelo que foi constatado, é componente digno de nota na evolução do relevo.
Para além dos resultados cartográficos, o processo pode ser aferido nos espessos pacotes coluviais que figuram como importantes depósitos correlativos. Os processos retrativos, no entanto, coexistem com um controle tectônico bem marcado que atua na manutenção dessas landforms e que se projeta em uma série de evidências: facetamento trapezoidal das escarpas, desvios de linhas interfluviais, entalhe vertical pronunciado, presença de vales suspensos, ocorrência de afloramentos rochosos em terraços, etc. A despeito do recuo verificado para as escarpas pelo aprofundamento dos vales, a manutenção de rupturas abruptas ao longo do tempo fica evidente nos resultados obtidos a partir da mensuração de Smf (quadro 1).

Quadro 1: Valores do Î́ndice Sinuosidade da Escarpa Montanhosa (Smf) obtidos no contexto das altas cristas quartzíticas.

\begin{tabular}{|c|c|c|c|c|c|}
\hline TOPÔNIMO & ORIENTAÇÃO DA VERTENTE & SMF ATUAL & SMF 0,5 & SMF 1,0 & SMF 2,0 \\
\hline MANTIQUEIRA & LESTE (L) & 1,77 & 1,13 & 0,93 & 0,92 \\
\hline MANTIQUEIRA & OESTE (O) & 2,69 & 1,04 & 2,15 & 1,62 \\
\hline $\begin{array}{c}\text { SERRA DE } \\
\text { LIMA DUARTE }\end{array}$ & NORTE (N) & 1,33 & 1,31 & 1,22 & 1,95 \\
\hline $\begin{array}{c}\text { SERRA DE } \\
\text { LIMA DUARTE }\end{array}$ & SUL (S) & 1,41 & 1,86 & 1,76 & 1,68 \\
\hline $\begin{array}{c}\text { SERRA } \\
\text { NEGRA }\end{array}$ & NORTE (N) & 1,42 & 1,15 & 1,39 & 1,67 \\
\hline $\begin{array}{c}\text { SERRA } \\
\text { NEGRA }\end{array}$ & SUL (S) & 1,18 & 1,33 & 1,25 & 1,62 \\
\hline $\begin{array}{c}\text { SERRA DO } \\
\text { IBITIPOCA }\end{array}$ & LESTE (L) & 2,95 & 2,05 & 1,71 & 1,60 \\
\hline
\end{tabular}

Mensurado para diferentes vertentes das escarpas montanhosas, os resultados apontam que em quatro situações a sequência de valores (da malha de 2,0 × 2,0 até a hipsometria atual) registrou aumento, o que indica uma acentuação do retrabalhamento sinalizada pelos valores mais elevados de Smf. Por outro lado, em três situações os valores tenderam à diminuição, sugerindo a manutenção das rupturas de declive abruptas nessas extensões em função dos esforços tectônicos, que se consorciam à resistência das estruturas quartzíticas na manutenção das serras. As diminuições mais expressivas foram verificadas na Serra Negra, francamente retilínea, e na vertente norte da Serra de Lima Duarte. Outra tendência observada diz respeito ao aumento de Smf na passagem da malha de 0,5 × 0,5 para a topografia atual, que se repete em cinco situações, sendo que a referida tendência se mostrou mais tênue na Serra Negra e na vertente norte da Serra de Lima Duarte.

Com a sobreposição das quatro linhas de ruptura (a atual e as obtidas em três malhas) foi possível averiguar as tendências de avanço, manutenção e retração por meio das medições sistemáticas que foram levadas a efeito, cujos resultados estão compilados no quadro 2. Em associação aos dados de Smf, permitem apontar algumas tendências evolutivas para as escarpas em apreço.

Pelo que se observa, a diminuição do número de pontos encontrados à frente das paleolinhas é acompanhado de um aumento de pontos encontrados na sua retaguarda, indicando tendência de regressão. Quando a tendência é contrária, aumento de número de pontos à frente da paleolinha associado à diminuição atrás, a conjectura mais plausível é de reafeiçoamento das escarpas, com formação de degraus e patamares que podem explicar seu avanço frente às linhas pretéritas. Malgrado as vertentes mensuradas serem dissecadas por rios de elevada agressividade erosiva, as medições mostram uma tendência de aumento do número de pontos à frente das paleolinhas, indicando constante reafeiçoamento do relevo. 
Quadro 2: Tendências de posicionamento da escarpa atual em relação à paleotopografia.

\begin{tabular}{|l|c|}
\multicolumn{2}{|c|}{ TOPÔNIMOSIORIENTAÇÖES } \\
\hline MANTIQUEIRA & LESTE (L) \\
\hline MANTIQUEIRA & OESTE (O) \\
\hline SERRA DE LIMA DUARTE & NORTE (N) \\
\hline SERRA DE LIMA DUARTE & SUL (S) \\
\hline SERRA NEGRA & NORTE (N) \\
\hline SERRA NEGRA & SUL (S) \\
\hline SERRA DO IBITIPOCA & LESTE (L) \\
\hline
\end{tabular}

\begin{tabular}{|c|c|c|}
\hline \multicolumn{3}{|c|}{ PONTOS A FRENTE DA PALEOLINHA } \\
\hline $2,0 \mathrm{~km}$ & $1,0 \mathrm{~km}$ & $0,5 \mathrm{~km}$ \\
\hline 24 & 33 & 18 \\
\hline 8 & 39 & 46 \\
\hline 18 & 26 & 26 \\
\hline 2 & 17 & 15 \\
\hline 8 & 48 & 26 \\
\hline 10 & 36 & 10 \\
\hline 43 & 55 & 57 \\
\hline
\end{tabular}

\begin{tabular}{|c|c|c|}
\hline \multicolumn{3}{|c|}{ PONTOS NA RETAGUARDA DA PALEOLINHA } \\
\hline $2,0 \mathrm{~km}$ & $1,0 \mathrm{~km}$ & $0,5 \mathrm{~km}$ \\
\hline 28 & 29 & 42 \\
\hline 59 & 37 & 4 \\
\hline 9 & 0 & 2 \\
\hline 14 & 7 & 9 \\
\hline 52 & 14 & 34 \\
\hline 40 & 10 & 37 \\
\hline 60 & 48 & 45 \\
\hline
\end{tabular}

Esses resultados indicam um padrão pelo qual as frentes escarpadas apresentam zonas de forte entalhe fluvial retraindo as escarpas e formando alcovas erosivas e reentrâncias côncavo-retilíneas. Essas geoformas se intercalam com degraus vinculados às reativações neotectônicas formadoras de noses que avançam além da escarpa mais recuada e encontram-se atualmente reafeiçoados em interflúvios locais. Essa configuração associada às evidências morfológicas contextualizadas sugere um controle morfotectônico favorecendo a dissecação e, sincronicamente, a formação de um relevo em patamares, com tendência de acentuação dos declives. Verticalmente, é notório o aprofundamento dos vales associado à manutenção das altitudes culminantes no horst.

Sustentadas em quartzitos dobrados, as cristas em discussão estabelecem contatos tectônicos com os compartimentos intermontanos, a despeito do contraste de resistência entre os litotipos quartzíticos que balizam os horsts e os gnaisses que embasam as morrarias policonvexas. Rupturas de declive assinaladas por soleiras tectônicas escalonadas definem o padrão de contato, com formação de vales suspensos e facetamento trapezoidal das escarpas, terraços soerguidos e com afloramentos rochosos, entre outras evidências de controle morfotectônico. Estudos sobre o papel da tectônica cenozoica na evolução do relevo regional são copiosos na literatura nacional (SAADI, 1991; GONTIJO, 1999; HIRUMA e RICCOMINI, 1999; SANTOS, 1999; RIBEIRO, 2003; CHIESSI, 2004; MORALES, 2005; SILVA e MELLO, 2011; MARQUES NETO, 2012; SILVA et al. 2017), reconhecendo diferentes campos de tensão atuantes ao longo do Neógeno e adentrando o Holoceno. A figura 7 ilustra algumas entre as conspícuas evidências que se fez menção acerca do controle morfotectônico vigente.

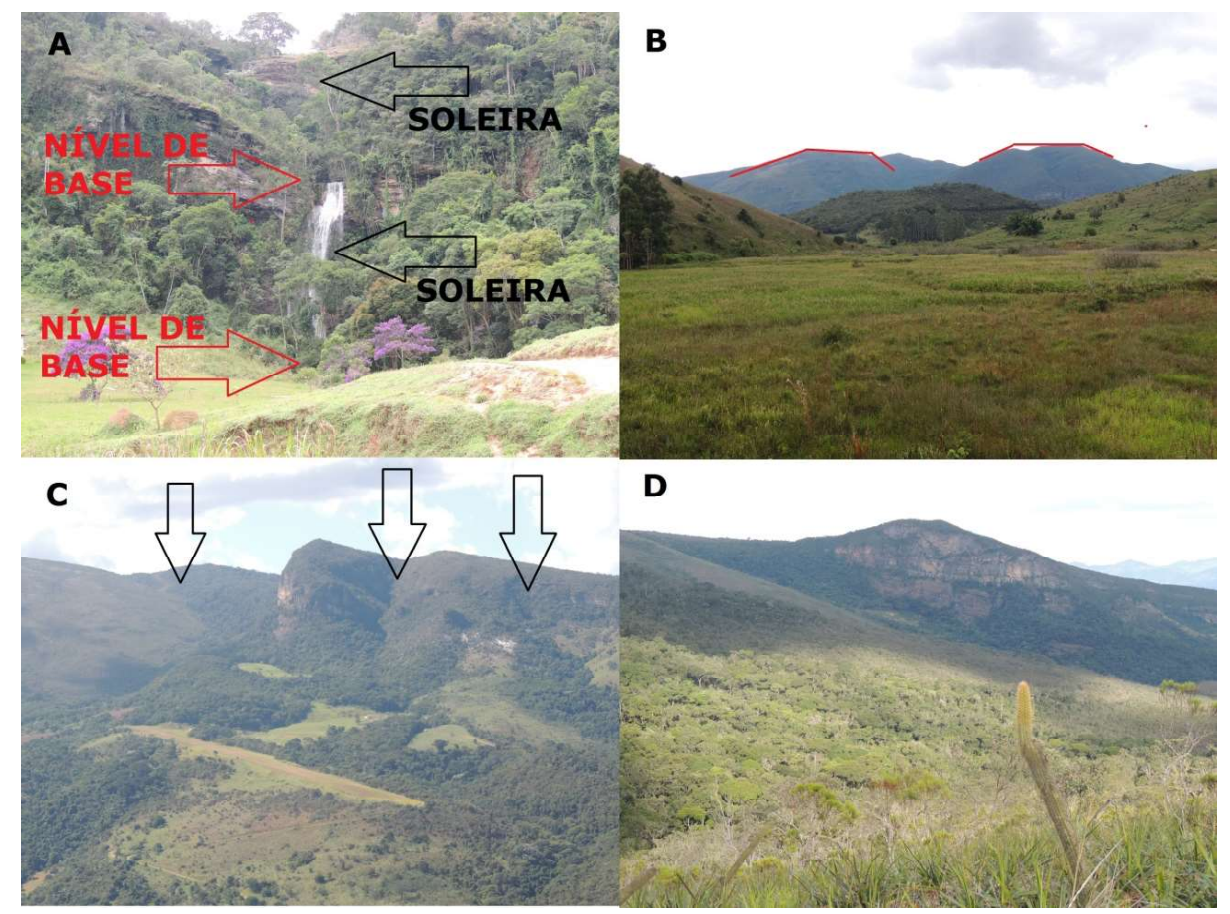

Figura 7 - Evidências morfológicas de controle tectônico na área de estudo. (A) Sequência de soleiras e níveis de base locais escalonados indicativos de reativação. (B) Relevo escarpado com facetas trapezoidais na Serra Negra; em primeiro plano, minigráben posicionado entre a Serra Negra e de Lima Duarte. (C) Vales suspensos em padrão paralelo dissecando as escarpas e patamares reafeiçoados da Serra do Ibitipoca. (D) Escarpa de falha com vales encaixados e profundos na Serra do Ibitipoca. 
O controle morfotectônico explica porque malgrado o estreitamento dos divisores as altitudes são mantidas em pontos culminantes, sendo até mesmo mais expressivas em alguns pontos, notoriamente no prolongamento NE da Serra do Ibitipoca (transecto A-A'). Certamente, a resistência dos quartzitos contribui para a sustentação desses blocos, mas os níveis elevados também perpassam os litotipos gnáissicos nas extremidades W e SW (figura 2), e as evidências morfológicas aventadas são onipresentes nos patamares de cimeira. Esse bloco em específico mantém elevações de destaque desde a malha de 2,0 $\times 2,0$, sugerindo se tratar de um compartimento morfotectônico definido por seu soerguimento preferencial em relação ao restante da estrutura. De fato, limita-se de forma distinta por superfícies de cimeira com aplainamentos irregulares ladeadas por escarpas de falha abruptas nas quais operam capturas fluviais e arranjo anômalo da drenagem, características que definem o alto e médio curso do ribeirão do Salto, principal curso d'água que disseca o compartimento. Ainda, o rebaixamento erosivo ocorrido entre a Serra Negra e a Serra de Lima Duarte também indica controle ativo na evolução do gráben dissecado pelo ribeirão Monte Verde, com espalhamento de depósitos correlativos em praticamente toda a extensão do compartimento, ainda retidos na paisagem e identificáveis em campo.

Estudos no campo da neotectônica são conclusivos ao apontarem o controle ativo na região dos grandes escarpamentos das bordas cratônicas do Brasil Oriental, explicando, em parte, que malgrado a retração erosiva das escarpas, sistemas geomorfológicos montanhosos persistem ao longo das faixas móveis pré-cambrianas (HIRUMA e RICCOMINI, 1999; SANTOS, 1999; HARTWIG e RICCOMINI, 2006 SILVA e MELO, 2011). Rezende et al. (2013), investigando as capturas fluviais a partir de aplicações em pequenas bacias hidrográficas na Serra da Mantiqueira, embora tenham constatado um maior número de bacias captoras entre os canais que demandam o vale do rio Paraíba do Sul, as discrepâncias não se mostraram agudas, havendo também capturas conspícuas nos flancos escarpados interiores dissecados por canais que convergem para o rio Grande. Ainda, os autores encontraram taxas de desnudação relativamente baixas para a Serra da Mantiqueira em comparação a outros escarpamentos de margem passiva, situadas entre 7,55 e $26,50 \mathrm{(m} /$ $\mathrm{Ma})$, o que em parte estaria relacionado à resistência do granito Maromba e do leucogranito Capivara, bem como a um último evento tectônico mais significativo de soerguimento generalizado ocorrido entre o Plioceno Superior (VALADÃO, 2009) e o Pleistoceno Inferior a Médio (SAADI, 1993). Os efeitos de rejuvenescimento da paisagem e ajuste da drenagem decorrentes desse evento teriam estendido seus efeitos até o Pleistoceno Médio (REZENDE et al. 2013).

A maior semelhança entre os perfis gerados para as malhas de $1,0 \times 1,0$ e $0,5 \times 0,5$ converge na visão supraexposta, aproximando, por conseguinte, a paleotopografia resultante na malha de 2,0 × 2,0 a uma configuração topográfica mais próxima daquela que possivelmente vigeu entre o Pleistoceno Inferior a Médio, ou até mesmo Plioceno. Ainda que os procedimentos de reconstrução paleotopográfica não figurem como métodos geocronológicos, as diferenças altimétricas observadas nos perfis, quando confrontadas com as taxas de desnudação supracitadas, fazem essa calibração.

Ainda que seja plausível considerar que reajustes significativos na compartimentação do relevo e em seus aspectos morfográficos não tenham sido a tônica na evolução da paisagem no último milhão de anos, vale ressaltar que a Serra da Mantiqueira é encimada em altitudes elevadas contínuas que definem um nível planáltico superior que tangencia diferentes litotipos: gnaisses, granitos, quartzitos, nefelina-sienitos, granulitos, etc. Tais superfícies albergam vales suspensos com estocagem de sedimentos desarticulados de níveis de base locais, que, por sua vez, apresentam copiosos terraços com presença de solos hidromórficos, horizontes orgânicos, bem como depósitos de acresção vertical e lateral. Estes depósitos são geneticamente vinculados aos ambientes de planícies fluviais e atualmente alçados em relação às planícies ativas em desníveis que ultrapassam 3 metros. Datações destes sedimentos por Luminescência Opticamente Estimulada amostradas em diferentes pontos distribuídos ao longo da Mantiqueira Meridional (MARQUES NETO, 2012) apontaram idades neoquaternárias, do Pleistoceno Superior ao Holoceno. Não raro, esses sedimentos são interpenetrados pelo substrato em afloramentos anômalos em fundos de vale, sugerindo persistência dos efeitos diastróficos tectônicos ao longo do Holoceno, com campos de tensão vigentes já apontados por autores como Riccomini et al. (2004) e Silva e Mello (2011).

Embora pairem dúvidas a respeito da influência destes campos de tensão mais recentes no relevo e nos processos erosivos e deposicionais, os depósitos que 
foram datados indicam incisão da drenagem e retrabalhamento de sedimentos mais antigos, circunstancialmente preservados na paisagem atual. Datações em rampas de colúvios não retrabalhadas e de sedimentos em vales colmatados suspensos poderiam trazer à baila informações geocronológicas a se somarem às existentes, permitindo um estreitamento do diálogo entre as técnicas de datação absoluta e as abordagens cartográficas voltadas para a reconstituição paelotopográfica.

\section{Conclusões}

A reconstituição paleotopográfica a partir da técnica Seppômen não figura como balizadora cronológica, ainda que, no plano cartográfico, seja capaz de fornecer elementos interessantes concernentes à evolução do relevo. Também demonstra capacidade de interação com outras frentes metodológicas, aproximando o diálogo entre as abordagens geomorfométricas, morfotectônicas, geoquímicas e geocronológicas. Ainda, possui caráter eminentemente quantitativo, podendo ser operacionalizada mediante expedientes de geoprocessamento, sendo que as informações paleotopográficas produzidas permitem averiguar influência tectônica a partir da persistência de feições escarpadas ao longo do tempo além dos resilientes quartzitos ou em função do entalhe fluvial e acentuação dos declives, por exemplo. As sequências de mapas também podem subsidiar a interpretação de dados geocronológicos e de desnudação geoquímica, possibilitando associações entre as paleossuperfícies espacializadas e esses dados absolutos. Embora os produtos cartográficos não tenham dimensão geocronológica, suas malhas engendram um significado temporal, tão caro aos métodos geocronológicos absolutos.

Essa trama de relações assume significados próprios em relevos montanhosos, enfaticamente no domínio dos grandes escarpamentos do Brasil Sudeste, onde os processos retrativos das escarpas montanhosas se consorciam ao soerguimento da massa siálica vigente ao longo do Cenozoico. Nesse sentido, a abordagem metodológica adotada reforçou a possibilidade de prevalência de atividade tectônica sustentando as feições escarpadas estudadas, sugerindo que essas landforms tem sido preservadas dos processos denudacionais cenozoicos tanto por controle tectônico como estrutural. Em contrapartida, a sequência de mapas e perfis mostra a tendência de rebaixamento nos domínios gnáissicos das superfícies intermontanas, onde são comuns sapro- litos profundos atualmente exumados, engendrando os desnivelamentos atuais vigentes na paisagem regional.

As altas cristas quartzíticas são marcadas por distinto escalonamento, com escarpas retilíneas e recuadas em relação aos patamares reafeiçoados, mantenedores de feições trapezoidais a despeito dos processos erosivos retrativos. Sua gênese e evolução, a luz do que foi interpretado, sugerem um diálogo entre o modelo teórico de W. Penck (1953) e o modelo do soerguimento isostático flexural (SUMMERFIELD, 1991; GILCHRIST e SUMMERFIELD, 1994). Os resultados explorados no presente paper denunciam os processos tectônicos e erosivos concomitantes, sendo que os mesmos operam em grandes escarpamentos de margens rifte, que tendencialmente soergue diante dos falhamentos de fundo e subsidência das bacias costeiras acolhedoras da massa continental desnudada. Aplicada nesses contextos de margem passiva com reativações intraplaca, a abordagem metodológica trabalhada estabelece capilaridade com esses dois modelos teóricos, francamente dialógicos na interpretação da gênese e evolução do relevo na região dos grandes escarpamentos do Brasil Oriental.

\section{Referências Bibliográficas}

BISHOP, P. Drainage rearrangement by river capture, beheading and diversion. Progress in Physical Geography, v. 19, n. 4, p. 449-473, 1995. DOI: 10.1177/030913339501900402

CHEREM, L. F.; VARAJÃO, C. A.; MAGALHÃES JR. A.; VARAJÃO, A. F. D. C.; SALGADO, A. A. R.; OLIVEIRA, L. A. F.; BERTOLINI, W. Z. O papel das capturas fluviais na morfodinâmica das bordas planálticas do sudeste do Brasil. Revista Brasileira de Geomorfologia, v. 14, n. 4, p. 299-308, 2013. DOI: http://dx.doi.org/10.20502/rbg.v14i4.325

\section{CHIESSI, C. M. Tectônica Cenozoica no Maciço Alcalino} de Passa Quatro (SP-MG-RJ). Dissertação (Mestrado em Geologia). Instituto de Geociências, Universidade de São Paulo, São Paulo, 2004. 146p.

COUTO, E. V.; FORTES, E.; SORDI, M. V.; MARQUES, M. J.; CAMOLEZI, B. A. Seppômens maps for geomorphic developments analysis: the case of Parana Plateau border, Faxinal, State of Parana, Brazil. Acta Scientarium Technology, v. 34, n. 1, p. 71-18, 2012. DOI: https://doi.org/10.4025/ actascitechnol.v34i1.9944

GONTIJO, A. H. F. Morfotectônica do médio vale do Rio Paraíba do Sul: região da Serra da Bocaina, estados de São Paulo e Rio de Janeiro. Tese (Doutorado em Geologia). Instituto 
de Geociências e Ciências Exatas, Universidade Estadual Paulista. Rio Claro, 1999. 259p.

GILCHRIST, A. R.; SUMMERFIELD, M. A. (1994) Tectonic models of passive margin evolution and their implications for theorys of long-term landscape development. In: KIRKBY, M. J. (Ed.) Process models and Theoretical Geomorphology. Jon Wiley \& Sons: p. 55-84.

HARTWIG, M. E.; RICCOMINI, C. Análise morfotectônica da região da Serra dos Órgãos, sudeste do Brasil. Revista Brasileira de Geomorfologia, v. 11, n. 1, p. 11-20, 2010. DOI: http://dx.doi. org/10.20502/rbg.v11i1.137

HEINEK, C. A.; SOUZA, H. A.; VASCONCELOS, R. M.; BARRETO, E. L.; GOMES, R. A. A. D.; PINTO, C. P. Programas Levantamentos Geológicos Básicos do Brasil. Companhia de Pesquisa de Recursos Minerais. Folha SF.23X-C-VI, 1991.

HIRUMA, S. T; RICCOMINI, C. Análise morfométrica em neotectônica: o exemplo do Planalto de Campos do Jordão. Revista do Instituto Geológico, São Paulo, USP, v. 20, n.1ㄹ, p. 5-19, 1999. DOI: 10.5935/0100-929X.19990001

LEVERINGTON, D. W.; TELLER, J. T. Paleotopographic reconstructions of the eastern outlets of glacial Lake Agassiz. Canadian Journal Earth Science, n. 40, p. 1259-1278, 2003. DOI: $10.1139 / \mathrm{e} 03-043$

MARQUES NETO, R. Estudo evolutivo do sistema morfoclimático e morfotectônico da bacia do Rio Verde (MG), sudeste do Brasil. Tese (Doutorado em Geografia). Instituto de Geociências e Ciências Exatas, Universidade Estadual Paulista, Rio Claro, 2012. 430p.

MORALES, N. Neotectônica em ambiente intraplaca: exemplos da região Sudeste do Brasil. Tese (Livre Docência em Geologia Estrutural e Geotectônica), Instituto de Geociências e Ciências Exatas, Universidade Estadual Paulista, Rio Claro, 2005. 201p.

MOTOKI, A. G.; PETRAKIS, H.; SICHEL, S. E.; CARDOSO, C. E.; MELO, R. C.; SOARES, R.; MOTOKI, K. F. Origem dos relevos do maciço sienítico do Mendanha, RJ, com base nas análises geomorfológicas e sua relação com a hipótese do vulcão de Nova Iguaçu. Geociências, v. 27, n. 1, p. 97-113, 2008.

MOTOKI, A. G.; CAMPOS, T. F. C.; FONSECA, V. P.; MOTOKI, K. F. Subvolcanic neck of Cabugi Peak, State of Rio Grande do Norte, Brazil, and origin of its landform. Revista da Escola de Minas, v. 62, n. 2, p. 195-206, 2012. DOI: http://dx.doi. org/10.1590/S0370-44672012000200008
PENCK, W. Morphological analysis of landforms. London: Maximilian and Co., 1953. 283p.

REZENDE, E. A..; SALGADO, A. A. R.; SILVA, J. R.; BOURLÈS, D.; BRAUCHER, R.; LÉANNI, L. Fatores controladores na evolução do relevo no flanco NNW do rif continental do sudeste do Brasil: uma análise baseada na mensuração de processos denudacionais de longo-termo. Revista Brasileira de Geomorfologia, v. 14, n. 2, p. 221-234, 2013. DOI: http://dx.doi.org/10.20502/rbg.v14i2.416

RIBEIRO, M. C. S. História tectônica e exumação das serras da Bocaina e Mantiqueira, SP/RJ. Dissertação (Mestrado em Geologia Regional), Instituto de Geociências e Ciências Exatas, Universidade Estadual Paulista, Rio Claro, 2003. 124p.

RICCOMINI, C. O rift continental do sudeste do Brasil. Tese de Doutorado, Instituto de Geociências, Universidade de São Paulo, São Paulo, 1989. 256p.

RICCOMINI, C.; SANT’ANNA, L. G.; FERRARI, A. L. (2004) Evolução geológica do Rift Continental do Sudeste do Brasil. In: MANTESSO-NETO, V. BARTORELLI, A.; CARNEIRO, C. D. R.; BRITO NEVES, B. B. (Org.) Geologia do Continente SulAmericano: evolução da obra de Fernando Flávio Marques de Almeida. Editora Beca, São Paulo: p. 407-421.

SAADI, A. Ensaio sobre a morfotectônica de Minas Gerais: tensões intraplaca, descontinuidades crustais e morfogênese. Tese (Professor Titular), Instituto de Geociências, Universidade Federal de Minas Gerais. Belo Horizonte, 1991. 285p.

Neotectônica da Plataforma Brasileira: esboço e interpretações preliminares. Geonomos, v.1, n.1, p.1-15,1993. DOI: https://doi. org/10.18285/geonomos.v1ile2.233

SALGADO, A. A. R.; CHEREM, L. F. S.; SORDI, M. V. Capturas fluviais no Brasil: síntese das novas descobertas. Estudos do Quaternário, n. 19, p. 23-31, 2018. DOI: https://doi.org/10.30893/ eq.v0i19.176

SANTOS, A. H. B. S. Rearranjos de dreangem na bacia do Rio Capivari e morfogênese da Serra do Mar em São Paulo (SP): uma contribuição ao estudo de capturas fluviais em meio tropical úmido. Tese (Doutorado em Geografia Física) Faculdade de Filosofia, Ciências e Letras, Universidade de São Paulo, São Paulo, 2017. 393p.

SANTOS, M. Serra da Mantiqueira e Planalto do Alto Rio Grande: a bacia terciária de Aiuruoca e evolução morfotectônica. Tese (Doutorado em Geociências) - Instituto de 
Geociências e Ciências Exatas, Universidade Estadual Paulista, Rio Claro, 1999. 134p.

SILVA, F. R.; MARQUES NETO, R.; MOREIRA, J. A.; RODRIGUES, E. L. N. Aspectos da tectônica ativa em bordas cratônicas: interpretações com base em dados geomorfométricos na região das altas cristas quartzíticas da Zona da Mata Mineira. Revista do Departamento de Geografia, v. esp. p. 218-226, 2017. DOI: https://doi.org/10.11606/rdg.v0ispe.132554

SILVA, T. P.; MELLO, C. L. Reativações neotectônicas na Zona de Cisalhamento do Rio Paraíba do Sul (sudeste do Brasil). Revista do Instituto de Geociências, v. 11, n. 1, p. 95-111, 2011. DOI: https://doi.org/10.5327/Z1519-874X2011000100006
SOARES, A. C. P; NOCE, C. M; TROUW, R. A. J; HEILBRON, M. Projeto Sul de Minas. COMIG-UFMG-UFRJ-UERJ, 2002.

SUMMERFIELD, M. A. Global Geomorphology: an introduction of the study of landforms. Essex, Longman \& Scientific Technical, 1991. 537p.

STRAHLER, A. N. Dynamic basis of geomorphology. Geological Society of American Bulletin, v. 63, p. 923-938, 1952. DOI: dx.doi.org/10.1130/0016-7606(1952)63[923:DBOG]2.0.CO;2

VARGAS, K. B. Superfícies geomorfológicas no centro norte paranaense e evolução do relevo regional. Tese (Doutorado em Geografia), Centro de Ciências Humanas, Letras e Artes, Universidade Estadual de Maringá, Maringá, 2017, 176p. 